Published in final edited form as:

Environ Int. 2015 October ; 83: 107-115. doi:10.1016/j.envint.2015.06.008.

\title{
Pharmacokinetics of Bisphenol A in Humans Following a Single Oral Administration
}

\section{Kristina A. Thayera, Daniel R. Doerge ${ }^{b}$, Dawn Hunt ${ }^{c}$, Shepherd H. Schurman ${ }^{c}$, Nathan C. Twaddle $^{\mathrm{b}}$, Mona I. Churchwell ${ }^{\mathrm{b}}$, Stavros Garantziotis ${ }^{\mathrm{c}}$, Grace E. Kissling ${ }^{\mathrm{d}}$, Michael R. Easterling $^{e}$, John R. Bucher ${ }^{a}$, and Linda S. Birnbaum ${ }^{f}$}

Kristina A. Thayer: thayer@niehs.nih.gov; Daniel R. Doerge: daniel.doerge@fda.hhs.gov; Dawn Hunt: dawnhunt2233@outlook.com; Shepherd H. Schurman: schurmansh@niehs.nih.gov; Nathan C. Twaddle: Nathan.Twaddle@fda.hhs.gov; Mona I. Churchwell: Mona.Churchwell@fda.hhs.gov; Stavros Garantziotis: garantziotis@niehs.nih.gov; Grace E. Kissling: kissling@niehs.nih.gov; Michael R. Easterling: MEasterling@s-3.com; John R. Bucher: bucher@niehs.nih.gov; Linda S. Birnbaum: birnbaumls@niehs.nih.gov

aDivision of the National Toxicology Program, National Institute of Environmental Health Sciences, National Institutes of Health, Department of Health and Human Services, P.O. Box 12233, Mail Drop K2-02, Research Triangle Park, NC USA 27709

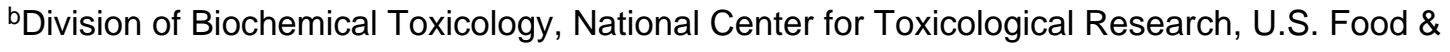
Drug Administration, NCTR-53C RM204L HFT-110, 3900 NCTR Road, Jefferson, AR USA 72079

${ }^{\circ}$ Clinical Research Unit, National Institute of Environmental Health Sciences, National Institutes of Health, Department of Health and Human Services, P.O. Box 12233, Mail Drop CU-01 Research Triangle Park, NC USA 27709

dBiostatistics Branch, National Institute of Environmental Health Sciences, P.O. Box 12233, Mail Drop A3-03, Research Triangle Park, NC USA 27709

eSocial \& Scientific Systems, Inc., 1009 Slater Rd \# 120, Durham, NC 27703

fNational Cancer Institute, National Institutes of Health, Department of Health and Human Services, P.O. Box 12233, Mail Drop B2-01, Research Triangle Park, NC USA 27709

\section{Abstract}

\footnotetext{
*Corresponding author: L.S. Birnbaum, National Institute of Environmental Health Sciences, P.O. Box 12233, B2-01, Research Triangle Park, North Carolina, NC 27709 USA. Telephone: (919) 541-3201; birnbaumls@niehs.nih.gov.

Contributors

LB conceived the study and contributed to the design and manuscript preparation. KAT and JRB contributed to the study design and manuscript preparation. DRD contributed to the design and conduct of the analytical determinations, model-independent pharmacokinetic evaluation, and manuscript preparation. DH, SS, and SG managed clinical aspects of the study and reviewed the manuscript. GEK and MRE provided statistical expertise and reviewed the manuscript. NCT conducted all analytical determinations for d6-BPA and metabolites; MIC conducted all analytical determinations for native BPA and bis-conjugated metabolites of d6-BPA.

Conflict of interest

The authors declare they have no competing financial interests with respect to this manuscript, or its content, or subject matter.

Disclaimer

The views presented in this article do not necessarily reflect those of the U.S. Food and Drug Administration.

Publisher's Disclaimer: This is a PDF file of an unedited manuscript that has been accepted for publication. As a service to our customers we are providing this early version of the manuscript. The manuscript will undergo copyediting, typesetting, and review of the resulting proof before it is published in its final citable form. Please note that during the production process errors may be discovered which could affect the content, and all legal disclaimers that apply to the journal pertain.
} 
Background-Human exposures to bisphenol A (BPA) are widespread. The current study addresses uncertainties regarding human pharmacokinetics of BPA.

Objective-To reduce uncertainties about the metabolism and excretion of BPA in humans following oral administration.

Methods-We exposed six men and eight women to $100 \mu \mathrm{g} / \mathrm{kg}$ bw of deuterated BPA (d6-BPA) by oral administration and conducted blood and urine analysis over a three day period. The use of d6-BPA allowed administered d6-BPA to be distinguished from background native (unlabelled) BPA. We calculated the rate of oral absorption, serum elimination, half-life, area under the curve (AUC), urinary excretion, and metabolism to glucuronide and sulfate conjugates.

Results-Mean serum total (unconjugated and conjugated) d6-BPA $\mathrm{C}_{\max }$ of $1711 \mathrm{nM}$ (390 $\mathrm{ng} / \mathrm{ml}$ ) was observed at $\mathrm{T}_{\max }$ of $1.1 \pm 0.50 \mathrm{~h}$. Unconjugated d6-BPA appeared in serum within 520 min of dosing with a mean $\mathrm{C}_{\max }$ of $6.5 \mathrm{nM}(1.5 \mathrm{ng} / \mathrm{ml})$ observed at $\mathrm{T}_{\max }$ of $1.3 \pm 0.52 \mathrm{~h}$. Detectable blood levels of unconjugated or total d6-BPA were observed at 48 hours in some subjects at concentrations near the LOD $(0.001-0.002 \mathrm{ng} / \mathrm{ml})$. The half-times for terminal elimination of total d6-BPA and unconjugated d6-BPA were $6.4 \pm 2.0 \mathrm{~h}$ and $6.2 \pm 2.6 \mathrm{~h}$, respectively. Recovery of total administered d6-BPA in urine was $84-109 \%$. Most subjects (10 of 14) excreted $>90 \%$ as metabolites within 24 hours.

Conclusions-Using more sensitive methods, our study expands the findings of other human oral pharmacokinetic studies. Conjugation reactions are rapid and nearly complete with unconjugated BPA comprising less than $1 \%$ of the total d6-BPA in blood at all times. Elimination of conjugates into urine largely occurs within 24 hours.

\section{Graphical Abstract}

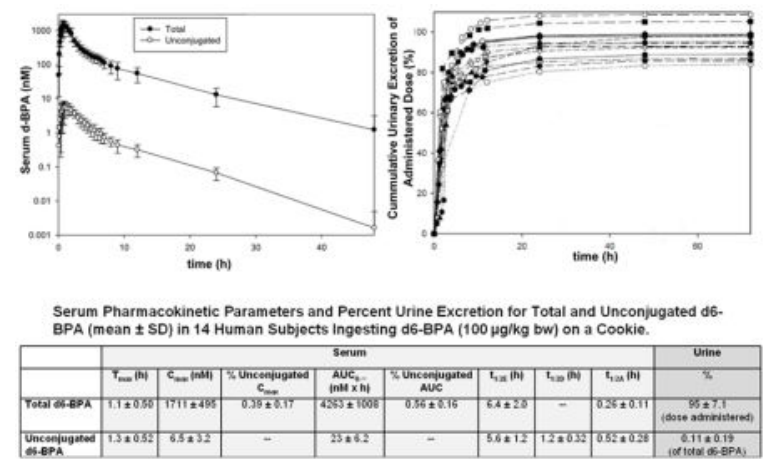

\section{Keywords}

deuterated bisphenol A; endocrine disruptor; ADME; bioavailability; metabolism; excretion

\subsection{Introduction}

Bisphenol A (BPA) is used in the manufacture of polycarbonate plastics, epoxy resins, and as a polymerization inhibitor in the formation of some polyvinyl chloride plastics.

Polycarbonates are in consumer products such as plastic dinnerware, microwave ovenware, eyeglass lenses, toys, pacifiers, impact-resistant safety equipment, compact discs and 
automobile parts. Epoxy resins are used in protective linings of canned food and beverage containers, drinking water storage tanks, wine vat linings, some paints, floorings, and some dental composites (EFSA 2013; FAO/WHO 2011; NTP 2008). Approximately 3\% of polycarbonate is used in the manufacture of medical devices (Hensten 2012). BPA is also a developer in thermal paper products such as cash register receipts and certain medical technical paper (EFSA 2013; Östberg and Noaksson 2010). Consequently, the potential for human exposure is widespread. Diet is considered the primary source of exposure to BPA for most people (EFSA 2006; FAO/WHO 2011; NTP 2008), although non-dietary contributions may be significant for certain sub-populations such as hospital patients and cashiers (Biedermann and others 2010; Calafat and others 2009; Lassen and others 2011).

BPA has been reported to cause a wide range of adverse health outcomes in experimental animal studies; some similar findings in humans have also been linked to BPA exposure in observational epidemiology studies (WHO 2011). Exposures during fetal life or early postnatal development are of most concern because of the susceptibility of normal development to potential disruption and because BPA is metabolized and eliminated through conjugation enzyme systems that may not be fully developed in early life (Divakaran and others in press; Gerona and others 2013).

Following ingestion, the majority of BPA is quickly bound to glucuronic acid to produce BPA glucuronide (BPA-G), a metabolic process called glucuronidation that is carried out by enzymes primarily in the liver and gut (NTP 2008). To a lesser extent, unconjugated parent (commonly referred to as "free") BPA is converted to other metabolites, primarily BPA sulfate, or BPA-S ( ). Because the conjugated forms of BPA do not bind the estrogen receptor (ER) they are considered biologically inactive; however, a recent study found conjugated forms of BPA can perturb cellular responses in prolactemia cells, presumably through interactions with membrane ERa which mediates rapid signalling responses (Viñas and others 2013).

Biomonitoring data document that human exposure to BPA is widespread (Calafat and others 2008; Teeguarden and others 2013) but there is debate on the validity of reported measures of unconjugated BPA in whole blood, serum, or plasma. The essence of the controversy is that levels of unconjugated BPA reported in blood from adults collected outside a medical setting of $0.5-2 \mathrm{ng} / \mathrm{mL}(2.2-8.8 \mathrm{nM})$ are orders of magnitude higher than would be predicted based on the estimated daily intakes for adults, which are less than 0.5 $\mu \mathrm{g} / \mathrm{kg}$ bw/day (EFSA 2013). Some of the strongest data to support daily intakes in this range (and lower) are based on back calculations from total 24 hour urinary output in a group of 596 German men and women (Koch and others 2012). Unconjugated BPA was not detectable in serum or urine at any time point in the single previous human oral pharmacokinetic (PK) study where subjects recieved an oral dose of $\sim 54-90 \mu \mathrm{g} / \mathrm{kg}$ bw (Volkel and others 2002). However, the limit of detection in that study, $2.28 \mathrm{ng} / \mathrm{ml}(10 \mathrm{nM})$, is less sensitive than more recent capabilities of 0.06 to $0.4 \mathrm{ng} / \mathrm{ml}(0.26$ to $1.75 \mathrm{nM})$ (Mortensen and others 2014; Vandenberg and others 2014; Vom Saal and others 2014). A recent study using a more sensitive method (LOD range of 0.02-0.96 ng/mL) reported a maximum concentration of unconjugated d6-BPA of $0.098 \mathrm{ng} / \mathrm{ml}(0.43 \mathrm{nM})$ at 1.6 hours following administration of $30 \mu \mathrm{g} / \mathrm{kg}$ bw of BPA in soup to 10 men (Teeguarden and others 
2015). The unconjugated d6-BPA was $0.3 \%$ of the total d6-BPA, leading the authors to conclude that exposure from the diet and sublingual absorption are unlikely to account for some reported biomonitoring results for unconjugated BPA in the "ng/ml" range in blood. Furthermore, oral pharmacokinetic studies in mice, rats, and rhesus monkeys using isotopically labelled BPA indicate that intakes of 75 to over $1,000 \mu \mathrm{g} / \mathrm{kg}$ bw/day would be required in order to produce the levels of unconjugated BPA reported in the human literature assuming similar kinetic parameters (Doerge and others 2010a; Doerge and others 2011b; Doerge and others 2010b; Taylor and others 2011; Vom Saal and others 2014).

Collectively, these discrepancies led to a concern that detectable levels of unconjugated BPA in blood are artifacts related to sample preparation or storage, background contamination from labware and/or the analytical technique employed, or due to special exposure situations, e.g., hospitals where patients may be exposed to BPA from medical devices or in occupational settings (Calafat and others 2013; Chapin and others 2008; Dekant and Volkel 2008; Longnecker and others 2013; Mielke and others 2011; Teeguarden and others 2013; Twaddle and others 2010; Ye and others 2013). Others maintain the validity of the blood biomonitoring results because the reported measurements are consistent across a variety of studies using a range of analytical methods in which authors reported taking great care to avoid background contamination during sample collection and analysis (Vandenberg and others 2013; Vom Saal and Welshons 2014). Hypotheses for unconjugated BPA levels reported in the $\mathrm{ng} / \mathrm{ml}$ range in a subset of human blood biomonitoring samples include unknown sources of exposure to BPA (Vandenberg and others 2013), storage and release of unconjugated BPA from depot tissues (Stahlhut and others 2009), and the possibility of dermal, sublingual, or inhalation routes of exposure (Gayrard and others 2013; Hormann and others 2014; Vandenberg and others 2007; Vandenberg and others 2013).

\subsection{Objective}

The objective of this oral pharmacokinetic study was to characterize d6-BPA and d6-BPA glucuronide and sulfate in blood and urine over a period of 3 days after administration of a single oral dose of $100 \mu \mathrm{g} / \mathrm{kg}$ bw of d6-BPA using more sensitive analytical methods than in the past. A dose level of $100 \mu \mathrm{g} / \mathrm{kg}$ bw was selected to ensure our ability to detect measureable levels of unconjugated d6-BPA during the initial 24 hours of the study and to provide direct linkage to the dose levels administered in pharmacokinetic studies conducted in rats, mice, and non-human primates (Doerge and others 2010a; Doerge and others 2011b; Doerge and others 2010b). The use of d6-BPA allows the detection of orally administered BPA to be distinguished from both background and potential contaminating BPA.

\subsection{Materials and Methods}

Study methods are summarized below and the IRB approved protocol, blood and urine collection methods, lab processing instructions are available in Supplemental Materials, Parts A-D. 


\subsection{Subject eligibility and recruitment}

Men and non-pregnant women were recruited in 2012-2013 from the Raleigh Durham region of North Carolina. After a pre-screening interview and examination (e.g., physical examination and clinical laboratory analysis), healthy volunteers meeting the following criteria were considered eligible for study: male or female 25-45 years of age; able to fast overnight for at least 8 hours; able to understand and provide written informed consent; able to travel to the NIEHS Clinical Research Unit (CRU) for all required study visits; and agree to use contraception to avoid conceiving a child or not to donate eggs or sperm for six months following their participation in the study. Criteria for exclusion were uncontrolled diabetes, liver or kidney dysfunction or disease, anemia, pregnancy, current lactation, BMI less than 19 or greater than 35, recent blood donation, and use of the following medications within 48 hours of the exposure and for the study days following the exposure: salicylic acid, acetaminophen, ibuprofen, naproxen, mefenamic acid, diclofenac, gliclazide carbamazepine, valproic acid, cimetidine, sulfasalazine, amoxicillin and erythromycin. These medications were targeted because of concern they may affect glucuronidation of BPA (Verner and others 2010). Each participant completed a short questionnaire (see Supplementary Materials, Table S10) to collect demographic information including age, ethnicity, gender, and information about possible BPA exposure at home and work. Accrual of subjects into the study was intended to stop when statistical simulations indicated estimates of elimination half-life $(\lambda)$ and of volume of distribution $(V)$ were within $20 \%$ of their simulated mean values with probability at least 0.90 . Variability in $\lambda$ and $V$ for the first 14 subjects was low enough that simulations supported ending recruitment. All human subject research activities were conducted in accordance with protocols approved by the National Institute of Health Clinical Center Institutional Review Board (protocol number 12E-0089; clinicaltrials.gov identifier: NCT01573429). In addition, the participation of the NCTR laboratory was reviewed and approved by the Research in Human Subjects Committee of the U.S. Food and Drug Administration (RIHSC\# 12-036T).

\subsection{Study design}

2.2.1 Steps to control and monitor background BPA contamination-Although taking steps to control potential contamination was not essential for this labelled-BPA study, we monitored for background (unlabeled) contamination of BPA using methods previously described (Churchwell and others 2014; Twaddle and others 2010). Efforts to limit contamination of serum and urine samples by native (background) BPA were implemented initially (the first 4 subjects) by selecting collection and processing materials identified from prior work as having undetectable levels of BPA or because they were made from nonpolycarbonate plastic. Native BPA was detected in some of the samples collected from the first 4 subjects (Figure S3) and concerted attempts to control for background contamination were abandoned in the main study. Efforts to limit exposure to dietary or other sources of BPA were not rigorous as there is no reason to suspect that native BPA would alter d6-BPA pharmacokinetic findings because prior reports of BPA kinetics in a variety of species, including humans, have reported approximately linear processes over a wide range of concentrations (Vandenberg and others 2007). 
2.2.2 Dosing—Subjects were fed a vanilla wafer cookie containing a dose of $100 \mu \mathrm{g} / \mathrm{kg}$ bw of d6-BPA after fasting starting at 12 midnight on the day of the visit. A single dosing solution $(10 \mathrm{mg} / \mathrm{ml}$ ) was prepared by dissolving d6-BPA in absolute ethanol (USP grade, Decon Laboratories, King of Prussia, PA). Aliquots of 0.5 and $1 \mathrm{ml}$ were placed in sealed screw-top glass vials, and stored chilled until just before dosing. The initial concentration of d6-BPA in the dosing solution $(10 \mu \mathrm{g} / \mu \mathrm{l})$ was verified by LC/MS/MS and concentrations in stored aliquots were always within $10 \%$ of the initial amount (range $93-106 \%$ ). Individual doses were administered by pipetting $10 \mu \mathrm{l}$ per $\mathrm{kg}$ bw onto a commercial vanilla wafer just before dosing (i.e., for a $70 \mathrm{~kg}$ person, $700 \mu \mathrm{l}$ containing $7 \mathrm{mg} \mathrm{d6-BPA}$ ). After a short delay to evaporate the solvent, the cookie was eaten and then the subject was provided a glass of water to drink.

2.2.3 Blood collection-After the insertion of an indwelling IV cannula/saline lock (Moore Medical, Part 66408; Insyte ${ }^{\mathrm{TM}}$ Autoguard $^{\mathrm{TM}}$ shielded IV catheters made of a polyurethane based BD Vialon ${ }^{\mathrm{TM}}$ biomaterial) and before the administration of d6-BPA, 17 $\mathrm{mL}$ of fasting blood was collected in red-top, additive-free, silicone-coated glass tube (Becton Dickinson Part 366431) for pre-dose determinations of d6-BPA andd6-BPA conjugates. After the participant finished the cookie, $7 \mathrm{~mL}$ of blood was collected at each time point over the course of $12 \mathrm{~h}$ via an inlying IV cannula/saline lock at 5, 10, 15, 20, 25, $30,40,45,50,60,80$ and 100 ( \pm 5 minutes), and 120, 150,180, 210, 240, 270 and $300( \pm 10$ minutes), and 330, 360, 390, 420, 480, 540 minutes ( \pm 15 minutes) and 720 minutes $( \pm 20$ minutes) post-d6-BPA ingestion (see Supplemental Materials Table S7 and Table S8 for details on collection times for individual subjects). An additional $7 \mathrm{~mL}$ peripheral blood draw was performed at $24 \mathrm{~h}$ (day 1), $48 \mathrm{~h}$ (day 2), and $72 \mathrm{~h}$ (day 3). Blood samples were taken by trained phlebotomists via the inlying catheter into glass tubes (Becton Dickinson Part 366431). Samples were allowed to clot at room temperature for at least 30 minutes, centrifuged, and then serum was stored at $-20^{\circ} \mathrm{C}$ in polypropylene microcentrifuge tubes (Sarstedt, Part \#76.690). Serum was analyzed as the preferred matrix since it was used in previous studies to represent circulating concentrations in blood. For the first 4 subjects, glass pipettes (Kimble Chase, Part \# 63B93-P) were used to transfer serum and polystyrene pipettes (CoStar part\# 4051) were used for subjects 5 to 14 . Vital signs were monitored for 12 hours following dosing. Blood samples for kidney and liver function testing (e.g., ALT, AST, ALP, creatinine, and blood urea nitrogen) were collected at the initial screening visit and on the last day of the study. The adequacy of the 3-day duration was initially evaluated on a pilot set of 3 participants who provided additional blood samples on day 4 and day 5 .

DNA samples were also collected to examine genes related to BPA metabolism. All known common functional genetic variants in $U G T 2 B 15$ (g. 253G > T; D85Y; g. 23490A >C; K523T; and g. $15486 C>T$; T352I), encoding the predominant BPA-glucuronidation enzyme, were analyzed (Bock and others 2010; Hanioka and others 2011). In addition, copy number variation in SULT1A1, encoding the predominant sulfotransferase responsible for BPA sulfation was determined (Nishiyama and others 2002) (see Supplemental Materials). However, genotypic analysis was considered ancillary to the goals of the PK study and it was recognized a priori that a sample size below 30 subjects would be underpowered to address the impact of genetic variation on pharmacokinetic parameters. Our stopping rules 
for subject enrolment described above were based on stability of pharmacokinetic measures and indicated we did not need to recruit this many subjects. For this reason we do not report genotypic analyses for the 14 subjects in our study, although the genotype data for each subject is available in Supplementary Materials, Table S6.

2.2.4 Urine collection-A fasting urine specimen was collected prior to the administration of the d6-BPA from polypropylene urine collection cups (Fisher Scientific 22-610-131 during the initial phase (subjects 1-4) and Moore Medical -AMSure ${ }^{\circledR}$ Urine Specimen Container Part\# 69716 for subjects 5-14). Following administration of the d6BPA, voiding behavior was unscheduled with participants collecting all urine in separate containers during post-dose intervals from $0-2,2-4,4-8$, and $8-12$ hours. At the end of the d6-BPA dosing day (Day 0), the clinic staff provided the participant with a 24-hour urine collection container (Thermo Scientific ${ }^{\mathrm{TM}}$ Samco $^{\mathrm{TM}}$ SW-3000 24-hour Urine Collection Containers from Fisher Scientific) as well as with an ice chest and frozen ice packs. Urines were kept on ice until frozen for storage at $-80^{\circ} \mathrm{C}$ until analysis. Creatinine and volume were measured on all urine samples.

\subsection{BPA measurements}

2.3.1 Materials-Native BPA, $\beta$-glucuronidase/arylsulfatase (Helix pomatia, $\mathrm{H} 1,16$ units/ $\mathrm{mg}$ ), unlabeled BPA-sulfate (BPA-S), and all other chemical reagents were purchased from Sigma Aldrich (St. Louis, MO) unless stated otherwise. ${ }^{13} \mathrm{C}_{12}$-BPA (>99\% isotopic purity) was obtained from Cambridge Isotope Labs (Andover, MA), d6-BPA (99.5 atom \%) from CDN Isotopes (Pointe-Claire, Quebec), unlabeled BPA-glucuronide (BPA-G; >99\% isotopic purity) from Toronto Research Chemicals (North York, Ontario, Canada), and ${ }^{13} \mathrm{C}_{12}$-BPA-G (>99\% isotopic purity) was synthesized by MRIGlobal (Kansan City, MO).

2.3.2 LC-ES/MS/MS Analysis of d6-BPA and Its Conjugates-Analysis of d6-BPA in urine and serum was performed by using validated high throughput UPLC-ES/MS/MS methods as previously described (Twaddle and others 2010) (see Supplemental Materials for additional details). Special precautions similar to those previously published (Doerge and others 2011a; Twaddle and others 2010) were used to minimize adventitious hydrolysis of conjugates during sample preparation. In brief, total serum concentrations of d6-BPA (i.e., unconjugated + conjugates) in serum and urine (0.1-10 $\mu \mathrm{l})$ were quantified following incubation with a H. pomatia glucuronidase/sulfatase mixture (Sigma Sulfatase H-1, 2 units/ assay). This preparation contains sufficient glucuronidase ( $\geq 300$ units/mg protein) and sulfatase ( $\geq 10$ units/mg protein) activity for total conjugate hydrolysis. The time course for deconjugation using each enzyme was determined from $0.25-24 \mathrm{~h}$ incubations using a pooled monkey serum sample obtained following oral dosing with d6-BPA, which contained primarily conjugated forms of BPA. Maximal enzymatic hydrolysis was observed after $2 \mathrm{~h}$ for the mixed glucuronidase/sulfatase and the purified sulfatase and after $24 \mathrm{~h}$ for the purified glucuronidase. Conjugate levels determined after total enzymatic hydrolysis were indistinguishable (t-test) from those derived from acid hydrolysis $\left(2 \mathrm{M} \mathrm{HCl}\right.$ at $99{ }^{\circ} \mathrm{C}$ for $2 \mathrm{~h}$; data not shown). 
Serum and urine samples from Subject 1 were pooled by mixing equal amounts of 30, 60, and 120 min samples as a "standard reference material" and included as a QC sample for the deconjugation process in every sample set. Values were in the range of $91-111 \%$ and $85-$ $117 \%$ with standard deviations of 6 and $8 \%$, respectively, for serum and urine.

Concentrations of unconjugated d6-BPA in $100 \mu \mathrm{l}$ aliquots of urine were determined without the enzymatic hydrolysis step using the same methodology described above for total d6BPA. Concentrations of unconjugated d6-BPA in $100 \mu \mathrm{l}$ aliquots of serum were measured without the enzymatic hydrolysis step using the pyridine-3-sulfonyl chloride derivatization procedure previously reported (Doerge and others 2011a). Method validation included analysis of d6-BPA spiked into serum samples on two different days at levels from $0.01-0.5$ $\mathrm{ng} / \mathrm{ml}$ with resulting intra- and inter-day accuracy and precision ranging from $92-110 \%$ and 4-30 \% RSD, respectively. The method detection limit for total d6-BPA, defined as a signal/ noise ratio of greater than or equal to 3 , was approximately $0.2 \mathrm{nM}(0.05 \mathrm{ng} / \mathrm{ml})$ in $100 \mu \mathrm{l}$ aliquots of serum using the negative ion electrospray LC/MS/MS procedures. For analysis of unconjugated d6-BPA in $100 \mu \mathrm{l}$ aliquots of serum using the derivatization procedure, the limit of detection (LOD, $\mathrm{S} / \mathrm{N}=3)$ was $0.004 \mathrm{nM}(0.001 \mathrm{ng} / \mathrm{ml})$.

Quality control measures were performed during every sample set, including the analysis of blank and d6-BPA spiked serum samples, a pooled human serum sample from this study containing primarily conjugated forms of BPA, blank injections, and injections of authentic standards. Pre-dosing serum and urine samples contained undetectable levels of d6-BPA.

Direct quantification of d6-BPA-G using isotope dilution negative ion LC-ES/MS/MS was performed using ${ }^{13} \mathrm{C}_{12}$-BPA-G as an internal standard similarly to that previously described (Churchwell and others 2014). The MS acquisition conditions are shown in Supplemental Material, Table S1. The approximate LOD for analysis of d6-BPA-G in 1-10 $\mu$ laliquots of urine was $3-30 \mathrm{ng} / \mathrm{ml}(7-70 \mathrm{nM})$ and for analysis of $10 \mu \mathrm{l}$ aliquots of serum the LOD was 1 $\mathrm{ng} / \mathrm{ml}(2 \mathrm{nM})$.

\subsection{Pharmacokinetic Analysis}

Plots of serum concentrations of total and unconjugated d6-BPA at each time point following oral administration were analyzed using model-independent pharmacokinetic analysis (PK Solutions 2.0 software, Summit Research Services, Montrose, CO). All data points collected were used for the graphical analyses described. Log-linear plots were fitted to up to three kinetic phases corresponding to elimination, distribution, and absorption processes. The first-order elimination rate constants $\left(\mathrm{k}_{\mathrm{E}}\right)$ for d6-BPA were determined from the terminal slope of the respective curve and the first-order distribution $\left(\mathrm{k}_{\mathrm{D}}\right)$ and/or absorption $\left(\mathrm{k}_{\mathrm{A}}\right)$ rate constants were determined after subtracting the contribution from the terminal elimination phase of the respective curve (i.e., feathering). The maximal concentration $\left(\mathrm{C}_{\max }\right)$ values were obtained from the time-concentration profiles at the time for maximal concentration $\left(\mathrm{T}_{\mathrm{max}}\right)$. The area under the time-concentration curve $\left(\mathrm{AUC}_{0-\infty}\right)$ was determined by using the arithmetic trapezoidal rule. Extrapolation for serum unconjugated d6-BPA beyond the last detectable measurement at the $24 \mathrm{~h}$ time point for $\mathrm{AUC}_{0-\infty}$ added approximately $1 \%$ to the arithmetic mean $\mathrm{AUC}_{0-24}$. The analytical and pharmacokinetic procedures followed in this study were identical to those used previously in 
Sprague-Dawley rats (Doerge and others 2010a), rhesus monkeys (Doerge and others 2010b), and CD-1 mice (Doerge and others 2011b), although the animal studies utilized gavage administration rather than food. Serum pharmacokinetics of d6-BPA-G and d6-BPA$\mathrm{S}$ were similarly determined using a subset of time points $(0.25-24 \mathrm{~h})$ from which terminal elimination and appearance phases were determined (Figure S2 and Table S9). The $\mathrm{AUC}_{0-\infty}$ was determined by using the trapezoidal rule and extrapolation for serum d6-BPA-G and d6BPA-S beyond the last detectable measurement at the $24 \mathrm{~h}$ time point for $\mathrm{AUC}_{0-\infty}$ added approximately $1 \%$ to the mean values for $\mathrm{AUC}_{0-24}$. Half-lives for all kinetic processes were determined from the rate constants using the relationship: half-life $\left(t_{1 / 2}\right)=\ln 2 / \mathrm{k}$. All data are presented as the mean $\pm \mathrm{SD}(\mathrm{n}=14)$ and the paired t-test was used to test significance of differences in pharmacokinetic parameters between unconjugated d6-BPA and total d6-BPA $(\mathrm{P}<0.05)$. Two-sample t-tests were used to compare pharmacokinetic parameters between the two race groups. Analysis of covariance was used to compare pharmacokinetic parameters between males and females, with and without adjusting for body surface area. Pvalues were two-sided.

\subsection{Results}

Results are summarized below and anonymized data for individual subjects are available in Supplemental Materials, Tables S6 to S10.

\subsection{Subject characteristics}

The average age of male $(n=6)$ and female $(n=8)$ volunteers was 34 years (range 26-45) and 30 years (range 26-39), respectively. Half of the subjects were non-Hispanic whites $(n=7)$ and half were African-Americans $(\mathrm{n}=7)$. The average BMI of male and female volunteers was 28.6 (23.8-33.4) and 26.1 (20.9-30.9), respectively. Two subjects reported working in occupations with higher potential BPA exposure, either the manufacture of polycarbonate plastic or as cashiers (Supplementary Materials, Table S10). A mild elevation in liver enzyme AST was observed in one subject during the 3-day post visit. When asked, the subject reported drinking several alcoholic beverages the night before.

\subsection{Pharmacokinetic analysis}

\subsubsection{BPA serum pharmacokinetics after oral administration-Following} administration of $100 \mu \mathrm{g} / \mathrm{kg}$ bw of d6-BPA on a cookie, serum contained measurable levels of total d6-BPA (i.e., conjugated forms) at the initial sampling point (5 min) and unconjugated d6-BPA was observed in individual serum profiles starting from 5-20 min (Figure 2). The $\mathrm{C}_{\max }$ was observed at a $\mathrm{T}_{\max }$ of $1.1 \pm 0.50 \mathrm{~h}$ (mean $\pm \mathrm{SD}$ ) for total d6-BPA and a $\mathrm{T}_{\max }$ of $1.3 \pm 0.52 \mathrm{~h}$ for unconjugated d6-BPA. The earlier occurrence of the $\mathrm{C}_{\max }$ for conjugated forms of d6-BPA, $\left(\mathrm{T}_{\max }\right)$, compared to parent compound in serum $(\mathrm{p}=0.08)$ was corroborated by kinetic analysis from which the appearance half-time for total $(0.26 \pm 0.11$ h) was significantly earlier than the absorption half-time for unconjugated $(0.52 \pm 0.28 \mathrm{~h})$ $(\mathrm{p}<0.0001)$. The half-times for distribution and terminal elimination of unconjugated d6BPA were $1.2 \pm 0.32 \mathrm{~h}$ and $5.6 \pm 1.2 \mathrm{~h}$, respectively. The half-time for terminal elimination of total d6-BPA was $6.4 \pm 2.0 \mathrm{~h}$, which was not significantly different from that for the unconjugated using the paired t-test. As shown in Figure 2 and, the unconjugated was a 
minor serum component comprising $0.39 \pm 0.17 \%$ of total d6-BPA at its $\mathrm{C}_{\max }$ and $0.56 \pm$ $0.16 \%$ of total d6-BPA in the $\mathrm{AUC}_{0-\infty}$. Over the $24 \mathrm{~h}$ time interval after dosing, the mean percentage of total d6-BPA present as unconjugated was $0.56 \%$ (Figure 2). For each $\mu \mathrm{g} / \mathrm{kg}$ bw of dose administered, the mean $\mathrm{C}_{\max }$ achieved for total d6-BPA was $3.9 \mathrm{ng} / \mathrm{ml}(17 \mathrm{nM})$ and $0.015 \mathrm{ng} / \mathrm{ml}(0.065 \mathrm{nM})$ for unconjugated d6-BPA. Detectable serum levels of unconjugated d6-BPA were observed at 48 hours in 3 of the 14 (21\%) subjects at concentrations near the LOD $(0.004-0.009 \mathrm{nM} ; 0.001-0.002 \mathrm{ng} / \mathrm{ml})$. Total d6-BPA was detectable at 48 hours in 4 of the $14(29 \%)$ subjects $(2.92-4.61 \mathrm{nM} ; 0.67-1.05 \mathrm{ng} / \mathrm{ml})$. However, the detectable levels at 48 hours were not observed in the same subjects for total d6-BPA (subjects \#1, 2, 3, 9) and unconjugated d6-BPA (subjects \#5, 7, 10). Neither total nor unconjugated d6-BPA was detected in any subject by 72 hours (Supplemental Material, Table S7). Overall, PK parameters did not vary based on sex (with the exception of AUC which was higher in males when not adjusted for surface area) or race.

3.2.2 Urinary excretion of d6-BPA-The goal was to collect and record entire urine volumes at every void during the course of blood collections $(12 \mathrm{~h})$ and on subsequent days. In general, this goal was achieved (i.e., the fraction of total administered dose recovered in urine as total d6-BPA was 84-109\%; and Figure 3). Subjects 4, 5, and 12 showed anomalously low total 3-day recovery $(55,48$, and $50 \%$ of the dose) and two of these subjects produced the lowest total urine volumes of the study. Therefore, a second round of dosing with only serial urine collections was conducted for these subjects and they were encouraged to consume more water in the clinic. The second round of dosing produced higher urine volumes than previously and these patients excreted 93,105 , and $109 \%$ of the administered dose, respectively. Data from the second round were used in the aggregate kinetic analysis for these subjects.

The subjects' voiding behavior was unconstrained, so collection times and urine volumes varied between subjects. From inspection of the individual urinary excretion profiles, approximately half of the administered dose was eliminated 1-3 $\mathrm{h}$ after dosing. Figure 3 presents the percentage of administered d6-BPA dose recovered in urine of individual subjects. By 24 hours, an average of 93\% (range $80-108 \%$ ) of each individual's total excreted d6-BPA was recovered with little additional recovery by the end of the study at 3 days (average 95\%, range 84-109\%) ( ). Cumulative d6-BPA urine recovery was $<90 \%$ in 4 of the 14 subjects (29\%). We were not able to determine conclusively the basis for the lower urine recovery in these subjects, i.e., lost urine during collection or individual variation in metabolism. We do not think low fluid intake was a factor since subjects drank 8 ounces of water with the cookie and were encouraged to drink fluids while at the CRU. We suspect, but could not verify, the most likely explanation is lost urine during collection (Harris and others 2000). When expressed as the fraction of total excreted dose (i.e., total urine concentration multiplied by the total urine volume collected over the three days, divided by the administered dose) an average of 94\% (range 86-98\%) of each individual's total excreted d6-BPA was recovered by the $12 \mathrm{~h}$ collection time and $98 \%$ (mean, range 92 $100 \%)$ by $24 \mathrm{~h}$.

Unconjugated d6-BPA was detected in post-dosing urine samples collected at times $<24 \mathrm{~h}$; however, the concentration of unconjugated d6-BPA in urine represented a small percentage 
of the total d6-BPA (geometric mean $0.029 \%$, range $0-1.1 \%$ ) present in each urine void at concentrations ranging from below the LOD to $98 \mathrm{ng} / \mathrm{ml}(420 \mathrm{nM})$. Concentrations of total d6-BPA in urine ranged from $\angle \mathrm{LOD}$ in pre-dose samples to $40,289 \mathrm{ng} / \mathrm{ml}(172,175 \mathrm{nM})$.

The ratios of total d6-BPA in urine and serum were evaluated at time points throughout the collection period when concurrent sampling and detectable levels were available. For each subject, an early ( $1 \mathrm{~h})$, an intermediate $(12 \mathrm{~h})$, and two late ( 24 and $48 \mathrm{~h})$ time points after dosing were used to compute the urine/serum ratio (geometric mean $=61$, range $2-1231$; Figure S1).

3.2.3 Analysis of d6-BPA conjugates in serum and urine-In addition to analysis of total d6-BPA in serum and urine samples after complete hydrolysis of conjugates, d6BPA-G and d6-BPA-S were analyzed individually to compare the two conjugation pathways. The mean $\mathrm{T}_{\max }$ values for d6-BPA-G in serum $(0.92 \mathrm{~h})$ were significantly shorter than those for d6-BPA-S (1.3 h, $\mathrm{p}<0.05)$, and d6 BPA-G appeared in serum significantly faster than d6-BPA-S ( $\mathrm{t}_{1 / 2}=0.31 \mathrm{~h}$ vs. $0.66 \mathrm{~h}$, respectively, $\mathrm{p}<0.05$ ) (Table 2 and Figure S2). Half-times for terminal elimination of d6-BPA-G or d6-BPA-S were not significantly different (Table 2). The serum $\mathrm{AUC}_{0-\infty}$ was approximately 3-fold greater for d6-BPA-G vs. d6-BPA-S (Table 2) and the average percentages of the total d6-BPA $\mathrm{AUC}_{0-\infty}$ present as d6-BPA-G and d6-BPA-S were $62 \pm 12$ and $23 \pm 7 \%$, respectively. In urine sample aggregates from all subjects, d6-BPA-G represented $87 \pm 6.9 \%$ of the total d6-BPA excreted and d6-BPA-S was $3 \pm 2.3 \%$ (Table 2). The apparent discrepancy between sums of the individually quantified conjugates and total conjugated d6-BPA prompted a search for evidence of bis-conjugated metabolites of d6-BPA (see Supplementary Materials for additional discussion). This was a qualitative exercise since unlabeled and labelled standards were not available for bis-conjugates, with the exception of native BPA-bis-sulfate. In brief, based on the similar LC retention time and analogous multiple reaction monitoring (MRM) responses, the d6-BPA-bis-sulfate was identified in urine from subject 9 at the $4 \mathrm{~h}$ time point (Figure S4) and in serum from subject 1 at the $0.7 \mathrm{~h}$ time point (Figure S5) because these samples had a large discrepancy and high concentrations of d6-BPA conjugates. Based on several MRMs derived from fragmentation of glucuronide, sulfate, and d6-BPA moieties, a mixed sulfate/glucuronide bis-conjugate was tentatively identified in both urine and serum with a retention time preceding that for d6-BPA-bis-sulfate.. No evidence for the presence of d6-BPA-bis-glucuronide was observed in either serum or urine; however, any conclusion regarding its absence must be considered tentative since its highly polar nature would lead to early elution in the chromatogram and therefore susceptible to suppression by coeluting matrix components.

\subsection{Discussion}

These human PK data are consistent with findings from similar studies of d6-BPA kinetics in experimental animal species following gavage and dietary administration (Doerge and others 2010a; Doerge and others 2011b; Doerge and others 2010b; Taylor and others 2011; Vom Saal and others 2014). This study also extends observations made in a previous human study of the kinetics of orally administered d6-BPA ( $\sim 54-90 \mu \mathrm{g} / \mathrm{kg}$ bw) performed by vikel et al. (2002). They reported that BPA delivered to human volunteers via a hard gelatin 
capsule was rapidly metabolized to BPA-G and unconjugated BPA was not detectable at any time point in blood or urine. However, the Vilkel et al. (2002) study had a LOD of 2.28 $\mathrm{ng} / \mathrm{ml}(10 \mathrm{nM})$, which is $\sim 2,500$ higher than the current study LOD of $0.001 \mathrm{ng} / \mathrm{ml}(0.004$ $\mathrm{nM}$ ). Similarly, Teeguarden et al. (2015) administered $30 \mu \mathrm{g} / \mathrm{kg}$ bw d6-BPA in soup and reported concurrent serum and urine concentration time profiles and pharmacokinetic analysis over a $24 \mathrm{~h}$ period for unconjugated and total d6-BPA, d6-BPAG, and d6-BPAS. Our findings are largely supportive of the earlier findings that orally administered BPA is rapidly absorbed, appearing in the blood as the glucuronide or sulfate conjugates within 15 minutes of administration. The serum $\mathrm{AUC}_{0-\infty}$ for d6-BPA-G was greater than that for d6BPA-S, and d6-BPA-G reached peak levels in blood significantly faster than the sulfate, although elimination half-times of the conjugates were similar. Measurable serum unconjugated d6-BPA appeared within 5-20 minutes and comprised $0.39 \%$ of total d6-BPA at its $\mathrm{C}_{\max }$ and $0.56 \%$ of total d6-BPA as $\mathrm{AUC}_{0-\infty}$. Our findings suggest the maximum serum concentrations in non-pregnant adults following ingestion of each $\mu \mathrm{g}$ of BPA per $\mathrm{kg}$ bw are $17 \mathrm{nM}(3.9 \mathrm{ng} / \mathrm{ml})$ of total and $0.065 \mathrm{nM}(0.015 \mathrm{ng} / \mathrm{ml})$ of unconjugated BPA. The results of the current study, Völkel et al. (2002), and Teeguarden et al. (2015) support the assumption used in urinary back-calculation models that almost $100 \%$ of oral BPA is excreted via urine as conjugates within 24 hours of exposure.

The improved detection limits of the current study allowed a better examination of the elimination rate at low blood levels of the unconjugated BPA. This was critical because a major goal of this study was to be able to address the controversy in the literature over whether reported levels of unconjugated BPA from human serum collected outside a medical or occupational setting are accurate. However, we were only partially succcessful in addressing this goal. By observing that less than $1 \%$ of total BPA is unconjugated BPA following oral intake, we would strongly suspect contamination if unconjugated BPA is in excess of $1 \%$ of total BPA following oral intake. Nonetheless, it remains a challenge to extrapolate this conclusion to individual samples collected from the general population for a number of reasons. First, exposure in the general population is not exclusively oral. Dermal exposure may occur where rapid first pass metabolism by the liver would not occur resulting in a higher percent of unconjugated BPA compared to oral. EFSA recently concluded that handling of thermal paper could be an important source of exposure for the general population above the age of 3 years, potentially contributing $7-15 \%$ to the total average BPA daily intake, although there is considerable uncertainty around the exposure estimates (EFSA 2013). We are currently initiating a dermal pharmacokinetic study of the same administered dose of $100 \mu \mathrm{g} / \mathrm{kg}$ bw using as many of the same subjects who participated in the oral study as possible. The results of the current oral study combined with results from the dermal study should help clarify the potential for dermal exposure to result in detectable levels of unconjugated BPA in serum. Also, Gayrard et al. (2013) reported high bioavailability of BPA (70\%) following sublingual exposure in dogs highlighting a limitation of gavage studies that do not capture sublingual or buccal absorption. The appearance of total conjugated d6-BPA species in serum before unconjugated d6-BPA and unconjugated percentages in $\mathrm{C}_{\max }$ below $1 \%$ of the total suggests that buccal absorption was not a significant factor for d6-BPA administered on a cookie that required chewing before ingestion. Similarly, Teeguarden et al. (2015) administered d6-BPA in soup to maximize 
contact of a liquid food with the oral mucosa and found no evidence for sublingual absorption. However, Hormann et al. (2014) recently reported increased serum unconjugated BPA in subjects who held thermal paper and ate French fries after using hand sanitizer. The average $\mathrm{C}_{\max }$ of $7.19 \mathrm{ng} / \mathrm{ml}$ occurred within 90 minutes (compared to baseline of 0.23 $\mathrm{ng} / \mathrm{ml}$ ) and was attributed to a combination of both dermal and sublingual/buccal absorption. Overall, a strong argument against the existence of other major sources of BPA exposure for most people is the fact that 24 hour urinary recoveries of BPA are considered to reflect an integration of daily exposure from all routes and these values generally agree with the estimated intakes from food alone (EFSA 2013; Koch and others 2012). The lingering challenges of interpreting serum BPA levels reinforces the conclusion that urine is preferred matrix for study of BPA to estimate total oral exposure (Calafat and others 2013; European Food Safety Authority (EFSA) 2013; Koch and Calafat 2009; Koch and others 2012; Ye and others 2013). Urine collection is non-invasive and offers a number of advantages compared to blood with respect to contamination factors, including a focus on the conjugated form which lessens issues of potential contamination, lower protein/lipid content which can influence solubilization of unconjugated BPA, larger volumes collected, and no need for use of sterile collection techniques and associated use of additional plastic supplies.

\subsection{Inter-individual differences in BPA pharmacokinetics}

Comparison of the absorption and elimination profiles suggested some inter-individual differences. The serum AUC for unconjugated d6-BPA values ranged from $12.1 \mathrm{nM} \times \mathrm{h}$ in subject 13 to $33.8 \mathrm{nM} \times \mathrm{h}$ in subject 11 , a 2.6-fold difference, and the corresponding $\mathrm{C}_{\max }$ values had a 4.4-fold difference with values ranging from $0.82 \mathrm{ng} / \mathrm{ml}(3.6 \mathrm{nM})$ to $3.6 \mathrm{ng} / \mathrm{ml}$ $(15.7 \mathrm{nM})$. The profiles for males and females were similar. Scatterplots of unconjugated Cmax and AUC suggest that subjects with greater BMI have higher unconjugated Cmax and AUCs; a larger sample size would be needed to confirm these associations. Higher blood concentrations as a function of increasing BMI when dosing is given on a body weight basis have been reported for other compounds (Jones 2007; McLeay and others 2012).

Consistent with the low LOD $(0.004 \mathrm{nM}$ or $0.001 \mathrm{ng} / \mathrm{ml})$ and $\mathrm{t}_{1 / 2 \mathrm{E}}$ (mean 6.2, range 4.4-8.4 h), low concentrations of unconjugated d6-BPA were detectable after 24 hours in all 14 subjects (mean $0.067 \mathrm{nM}$ or $0.015 \mathrm{ng} / \mathrm{ml}$ ). There were unexpected findings of detecting total or unconjugated d6-BPA at 48 hours in some subjects, although the detectable levels were not observed in the same subjects for unconjugated and total d6-BPA. We do not have a biological explanation for these findings and they may represent performance of the assay near the LOD. None of the subjects had detectable levels of total or unconjugated d6-BPA at 72 hours or beyond. Cumulative urine recovery was $<90 \%$ in 4 of 14 of subjects, some of whom also had detectable levels of unconjugated d6-BPA or total d6-BPA at 48 hours. We suspect but cannot confirm that the basis for the lower urine recovery in these subjects was lost urine during collection.

\subsection{Inter-species comparisons of BPA pharmacokinetics}

The pharmacokinetic behavior of d6-BPA has been reported in adult rodents and non-human primates using oral dosing and a similar analytical approach to that used in this human study. After oral gavage administration, circulating concentrations of unconjugated d6-BPA 
represent a small fraction of the total d6-BPA $\mathrm{C}_{\max }$ in the CD-1 mouse (0.45\%) (Doerge and others 2011b), Sprague-Dawley rat (0.55\%) (Doerge and others 2010a), rhesus monkey $(0.21 \%)$ (Doerge and others 2010b) and human $(0.39 \%)$. This consistently high degree of conjugation reflects the predominant role of pre-systemic metabolism in the gastrointestinal tract and liver in adults of these species that limits absolute bioavailability to $0.2 \%$ in mice, $2.8 \%$ in rats, and $0.94 \%$ in monkeys following oral gavage administration. These similarities in unconjugated bioavailability across species occur despite significant differences in the route of elimination of BPA between rodents and primates that presumably stem from the higher biliary cut-off point in rodents, affecting processes such as biliary excretion, enterohepatic recirculation, and fecal elimination in rodents compared to exclusively urinary excretion in primates.

\subsection{Study limitations}

This oral PK study does not address the extent to which exposure to BPA, by any route, may occur; nor does it assess the extent to which non-oral routes contribute to total exposures; nor does it assess how BPA is metabolized in individuals experiencing exposures from multiple routes (EFSA 2013). Contributions from sources of non-dietary exposure such as through thermal paper products and medical devices are poorly documented (EFSA 2013; Stahlhut and others 2009) and may be significant for certain sub-populations such as hospital patients and cashiers (Biedermann and others 2010; Calafat and others 2009; Lassen and others 2011). In order to address uncertainities regarding dermal exposure, we are undertaking an additional human pharmacokinetic study of BPA following dermal exposure to $100 \mu \mathrm{g} / \mathrm{kg}$ bw using many of the same subjects who participated in the current study.

This study also does not provide insight on BPA disposition in children, pregnant women, the elderly, nor does it provide a complete picture of population pharmacokinetic variability. The small number and relatively homogeneous composition of subjects (healthy adults 2545 years within a restricted BMI range who were either non-Hispanic white or African American) also precludes making inferences with respect to other sources of variation, such as ethnicity, genetic differences, or disease status.

\subsection{Conclusions}

We found the disposition of $100 \mu \mathrm{g} / \mathrm{kg}$ bw orally administered d6-BPA in adults to be consistent with data from experimental adult animal models, and consistent with the all other human pharmacokinetic studies. Maximum serum concentrations are $3.9 \mathrm{ng} / \mathrm{ml}$ (17 $\mathrm{nM})$ of total and $0.015 \mathrm{ng} / \mathrm{ml}(0.065 \mathrm{nM})$ of unconjugated BPA for each $\mu \mathrm{g}$ of BPA ingested per kg of body weight. Levels of unconjugated BPA in blood following oral administration are $<1 \%$ of the total.

\section{Supplementary Material}

Refer to Web version on PubMed Central for supplementary material. 


\section{Acknowledgments}

We gratefully acknowledge the contributions of Gail McCarver and Karthika Divakaran (Medical College of Wisconsin, Milwaukee, Wisconsin, USA) for conducting genotype analyses and Mike DeVito, Jeffrey Fisher, Jerry Heindel, and Matthew Longnecker for reviewing a draft version of the manuscript. Funding: This research was supported by the intramural research programs of the National Institute of Environmental Health Sciences and the National Cancer Institute, National Institutes of Health.

\subsection{References}

Biedermann S, Tschudin P, Grob K. Transfer of bisphenol A from thermal printer paper to the skin. Anal Bioanal Chem. 2010; 398:571-576. [PubMed: 20623271]

Bock, KW.; Burchell, B.; Guillemette, C.; Mackenzie, PI.; Nebert, DW.; Court, M.; Owens, I. [accessed 1 June 2014] UDP-Glucuronosyltransferase alleles nomenclature page for UGT2B/ UGT2B15 haplotypes. 2010. http://www.pharmacogenomics.pha.ulaval.ca/cms/site/ pharmacogenomics/ugt_alleles

Calafat AM, Koch HM, Swan SH, Hauser R, Goldman LR, Lanphear BP, Longnecker MP, Rudel RA, Teitelbaum SL, Whyatt RM, Wolff MS. Misuse of blood serum to assess exposure to bisphenol A and phthalates. Breast Cancer Research. 2013; 15:403. [PubMed: 24083327]

Calafat AM, Weuve J, Ye X, Jia LT, Hu H, Ringer S, Huttner K, Hauser R. Exposure to bisphenol A and other phenols in neonatal intensive care unit premature infants. Environ Health Perspect. 2009; 117:639-644. [PubMed: 19440505]

Calafat AM, Ye X, Wong LY, Reidy JA, Needham LLCINEHPJaP. Exposure of the U.S. population to bisphenol A and 4-tertiary-octylphenol: 2003-2004. Environ Health Perspect. 2008; 116:39-44. [PubMed: 18197297]

Chapin RE, Adams J, Boekelheide K, Gray LE Jr, Hayward SW, Lees PS, McIntyre BS, Portier KM, Schnorr TM, Selevan SG, Vandenbergh JG, Woskie SR. NTP-CERHR expert panel report on the reproductive and developmental toxicity of bisphenol A. Birth Defects Research Part B, Developmental and Reproductive Toxicology. 2008; 83:157-395.

Churchwell MI, Camacho L, Vanlandingham M, Twaddle NC, Sepehr E, Delclos KB, Fisher JW, Doerge DR. Comparison of lifestage-dependent internal dosimetry for bisphenol A, ethinyl estradiol, a reference estrogen, and endogenous estradiol to test an estrogenic mode of action in Sprague-Dawley rats. Toxicol Sci. Mar 13.2014 Epub ahead of print.

Dekant W, Volkel W. Human exposure to bisphenol A by biomonitoring: methods, results and assessment of environmental exposures. Toxicol Appl Pharmacol. 2008; 228:114-134. [PubMed: 18207480]

Divakaran K, Hines R, McCarver G. Human hepatic UGT2B15 developmental expression. Tox Sci. First published online: June 30, 2014; in press.

Doerge DR, Twaddle NC, Vanlandingham M, Brown RP, Fisher JW. Distribution of bisphenol A into tissues of adult, neonatal, and fetal Sprague-Dawley rats. Toxicol Appl Pharmacol. 2011a; 255:261-270. [PubMed: 21820460]

Doerge DR, Twaddle NC, Vanlandingham M, Fisher JW. Pharmacokinetics of bisphenol A in neonatal and adult Sprague-Dawley rats. Toxicol Appl Pharmacol. 2010a; 247:158-165. [PubMed: 20600215]

Doerge DR, Twaddle NC, Vanlandingham M, Fisher JW. Pharmacokinetics of bisphenol A in neonatal and adult CD-1 mice: inter-species comparisons with Sprague-Dawley rats and rhesus monkeys. Toxicol Lett. 2011b; 207:298-305. [PubMed: 21983029]

Doerge DR, Twaddle NC, Woodling KA, Fisher JW. Pharmacokinetics of bisphenol A in neonatal and adult rhesus monkeys. Toxicol Appl Pharmacol. 2010b; 248:1-11. [PubMed: 20655935]

European Food Safety Authority (EFSA). Opinion of the Scientific Panel on Food Additives, Flavourings, Processing Aids and Materials in Contact with Food on a request from the Commission related to 2,2-bis(4-hydroxyphenyl)propane (bisphenol A). EFSA J. 2006; 428:1-75. http://www.efsa.europa.eu/en/efsajournal/pub/428.htm. 
European Food Safety Authority (EFSA). [accessed 23 August 2013] Public consultation on the draft opinion on bisphenol A (BPA) - exposure assessment. 2013. p. 314http://www.efsa.europa.eu/en/ consultations/call/130725.htm

FAO/WHO. Joint Food and Agriculture Organization of the United Nations and World Health Organization (FAO/WHO) expert meeting to review toxicological and health aspects of bisphenol A: Final report, including report of stakeholder meeting on bisphenol A; 1-5 November 2010; Ottawa, Canada. 2011. http://www.who.int/foodsafety/chem/chemicals/bisphenol/en/

Gayrard V, Lacroix MZ, Collet SH, Viguie C, Bousquet-Melou A, Toutain PL, Picard-Hagen NCINEHPN-DAP. High bioavailability of bisphenol A from sublingual exposure. Environ Health Perspect. 2013; 121:951-956. [PubMed: 23761051]

Gerona RR, Woodruff TJ, Dickenson CA, Pan J, Schwartz JM, Sen S, Friesen MW, Fujimoto VY, Hunt PA. Bisphenol-A (BPA), BPA glucuronide, and BPA sulfate in midgestation umbilical cord serum in a northern and central California population. Environ Sci Technol. 2013; 47:1247712485. [PubMed: 23941471]

Hanioka N, Oka H, Nagaoka K, Ikushiro S, Narimatsu S. Effect of UDP-glucuronosyltransferase 2B15 polymorphism on bisphenol A glucuronidation. Arch Toxicol. 2011; 85:1373-1381. [PubMed: 21404072]

Harris SA, Purdham JT, Corey PN, Sass-Kortsak AM. An evaluation of 24-hour urinary creatinine excretion for use in identification of incomplete urine collections and adjustment of absorbed dose of pesticides. AIHAJ. 2000; 61:649-657. [PubMed: 11071416]

Hensten, A. The safety of the use of bisphenol A in medical devices. Presentation at EFSA Meeting with Member State Experts on Bisphenol A; Parma, Italy. 29-30 October 2012; 2012. http:// www.efsa.europa.eu/en/events/event/121029.htm and http://www.efsa.europa.eu/en/ supporting/doc/389e.pdf

Hormann AM, Vom Saal FS, Nagel SC, Stahlhut RW, Moyer CL, Ellersieck MR, Welshons WV, Toutain PL, Taylor JA. Holding thermal receipt paper and eating food after using hand sanitizer results in high serum bioactive and urine total levels of bisphenol A (BPA). PLoS ONE. 2014; 9:e110509. [PubMed: 25337790]

Jones AW. Body mass index and blood-alcohol calculations. J Anal Toxicol. 2007; 31:177-178. [PubMed: 17598284]

Koch HM, Calafat AM. Human body burdens of chemicals used in plastic manufacture. Philosophical Transactions of the Royal Society of London Series B, Biological Sciences. 2009; 364:2063-2078. [PubMed: 19528056]

Koch HM, Kolossa-Gehring M, Schroter-Kermani C, Angerer J, Bruning T. Bisphenol A in 24 h urine and plasma samples of the German Environmental Specimen Bank from 1995 to 2009: a retrospective exposure evaluation. J Expo Sci Environ Epidemiol. 2012; 22:610-616. [PubMed: 22617719]

Lassen, C.; Mikkelsen, SH.; Brandt, UK. Survey of Chemical Substances in Consumer Products, No. 110 2011. Danish Ministry of the Environment; 2011. Migration of bisphenol A from cash register receipts and baby dummies. http://www2.mst.dk/udgiv/publications/ 2011/04/978-87-92708-93-9.pdf [accessed 8 July 2013]

Longnecker MP, Harbak K, Kissling GE, Hoppin JA, Eggesbo M, Jusko TA, Eide J, Koch HM. The concentration of bisphenol A in urine is affected by specimen collection, a preservative, and handling. Environ Res. 2013 Jul 27. 10; 2013.

McLeay SC, Morrish GA, Kirkpatrick CM, Green B. The relationship between drug clearance and body size: systematic review and meta-analysis of the literature published from 2000 to 2007. Clin Pharmacokinet. 2012; 51:319-330. [PubMed: 22439649]

Mielke H, Partosch F, Gundert-Remy U. The contribution of dermal exposure to the internal exposure of bisphenol A in man. Toxicol Lett. 2011; 204:190-198. [PubMed: 21571050]

Mortensen ME, Calafat AM, Ye X, Wong LY, Wright DJ, Pirkle JL, Merrill LS, Moye J. Urinary concentrations of environmental phenols in pregnant women in a pilot study of the National Children's Study. Environ Res. 2014; 129:32-38. [PubMed: 24529000] 
National Toxicology Program (NTP). NTP-CERHR Monograph on the Potential Human Reproductive and Developmental effects of Bisphenol A. NTP CERHR Monograph Series. 2008; v:vii-ix. 1-64. passim http://ntp.niehs.nih.gov/ntp/ohat/Bisphenol/Bisphenol.pdf.

Nishiyama T, Ogura K, Nakano H, Kaku T, Takahashi E, Ohkubo Y, Sekine K, Hiratsuka A, Kadota S, Watabe T. Sulfation of environmental estrogens by cytosolic human sulfotransferases. Drug Metabolism and Pharmacokinetics. 2002; 17:221-228. [PubMed: 15618673]

Östberg, T.; Noaksson, E. [accessed 8 July 2013] Bisfenol A in Svenska Kvitton. Analysresultat. Institutet för Tillämoa Grön Kemi, Jämtlands läns Landstingb [in Swedish]. 2010. http:// www.jegrelius.se/wp-content/uploads/2014/01/Bisfenol-A-i-svenska-kvitton-Jegrelius-101013pdf-version.pdf

Stahlhut RW, Welshons WV, Swan SHCINEHPMAP. Bisphenol A data in NHANES suggest longer than expected half-life, substantial nonfood exposure, or both. Environ Health Perspect. 2009; 117:784-789. [PubMed: 19479022]

Taylor JA, Vom Saal FS, Welshons WV, Drury B, Rottinghaus G, Hunt PA, Toutain PL, Laffont CM, VandeVoort CACINEHPJA. author reply AP. Similarity of bisphenol A pharmacokinetics in rhesus monkeys and mice: relevance for human exposure. Environ Health Perspect. 2011; 119:422-430. [PubMed: 20855240]

Teeguarden J, Hanson-Drury S, Fisher JW, Doerge DR. Are typical human serum BPA concentrations measurable and sufficient to be estrogenic in the general population? Food Chem Toxicol. 2013; 62:949-963. [PubMed: 23959105]

Teeguarden JG, Twaddle N, Churchwell MI, Yang X, Fisher JW, Seryak LM, Doerge DR. 24-hour human urine and serum profiles of bisphenol A: Evidence against sublingual absorption following ingestion in soup. Toxicol Appl Pharmacol. 2015 Jan 22. 10; 2015.

Twaddle NC, Churchwell MI, Vanlandingham M, Doerge DR. Quantification of deuterated bisphenol A in serum, tissues, and excreta from adult Sprague-Dawley rats using liquid chromatography with tandem mass spectrometry. Rapid communications in mass spectrometry: RCM. 2010; 24:30113020. [PubMed: 20872634]

Vandenberg LN, Gerona RR, Kannan K, Taylor JA, van Breemen RB, Dickenson CA, Liao C, Yuan Y, Newbold RR, Padmanabhan V, Vom Saal FS, Woodruff TJ. A round robin approach to the analysis of bisphenol a (BPA) in human blood samples. Environ Health. 2014; 13:25. [PubMed: 24690217]

Vandenberg LN, Hauser R, Marcus M, Olea N, Welshons WV. Human exposure to bisphenol A (BPA). Reprod Toxicol. 2007; 24:139-177. [PubMed: 17825522]

Vandenberg LN, Hunt PA, Myers JP, Vom Saal FS. Human exposures to bisphenol A: mismatches between data and assumptions. Rev Environ Health. 2013; 28:37-58. [PubMed: 23612528]

Verner MA, Magher T, Haddad S. High concentrations of commonly used drugs can inhibit the in vitro glucuronidation of bisphenol A and nonylphenol in rats. Xenobiotica; the fate of foreign compounds in biological systems. 2010; 40:83-92.

Viñas R, Goldblum RM, Watson CS. Rapid estrogenic signaling activities of the modified (chlorinated, sulfonated, and glucuronidated) endocrine disruptor bisphenol A. Endocrine Disruptors. 2013; 1:0-9.

Volkel W, Colnot T, Csanady GA, Filser JG, Dekant W. Metabolism and kinetics of bisphenol a in humans at low doses following oral administration. Chem Res Toxicol. 2002; 15:1281-1287. [PubMed: 12387626]

Vom Saal FS, Vandevoort CA, Taylor JA, Welshons WV, Toutain PL, Hunt PA. Bisphenol A (BPA) pharmacokinetics with daily oral bolus or continuous exposure via silastic capsules in pregnant rhesus monkeys: Relevance for human exposures. Reprod Toxicol. 2014 Feb 17. pii: S0890-6238(14)00020-3. [Epub ahead of print]:10; 2014. 10.1016/j.reprotox.2014.01.007

Vom Saal FS, Welshons WV. Evidence that bisphenol A (BPA) can be accurately measured without contamination in human serum and urine, and that BPA causes numerous hazards from multiple routes of exposure. Mol Cell Endocrinol. 2014; 398:101-113. [PubMed: 25304273]

World Health Organization (WHO). Toxicological and Health Aspects of Bisphenol A. Report of Joint FAO/WHO Expert Meeting 2-5 November 2010 and Report of Stakeholder Meeting on Bisphenol 
A; 1 November 2010; Ottawa, Canada. 2011. http://www.who.int/foodsafety/chem/chemicals/ bisphenol/en/index 1.html

Ye X, Zhou X, Hennings R, Kramer J, Calafat AM. Potential external contamination with bisphenol A and other ubiquitous organic environmental chemicals during biomonitoring analysis: an elusive laboratory challenge. Environ Health Perspect. 2013; 121:283-286. [PubMed: 23458838] 


\section{Highlights}

- Findings are consistent with data from animal and other human studies.

- Maximum total serum levels are $3.9 \mathrm{ng} / \mathrm{ml}$ for each $\mu \mathrm{g}$ ingested per $\mathrm{kg}$.

- Maximum unconjugated serum levels are $0.015 \mathrm{ng} / \mathrm{ml}$ for each $\mu \mathrm{g}$ ingested per $\mathrm{kg}$.

- Unconjugated BPA in blood following oral administration is $<1 \%$ of the total.

- Most subjects excreted $>90 \%$ as conjugated metabolites within 24 hours. 


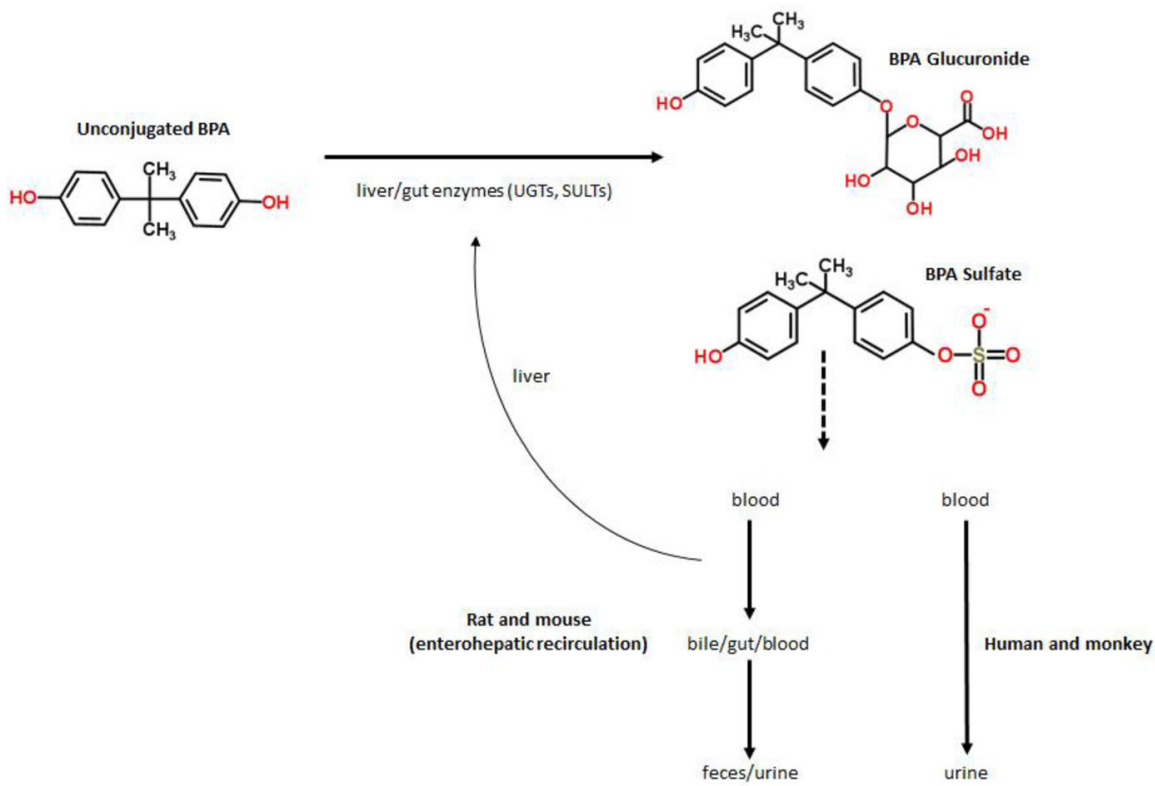

Figure 1. Overview of BPA metabolism

In humans, elimination is via the urine in the form of BPA or BPA conjugates, mostly BPA$\mathrm{G}$. The elimination routes in rodents include urine as well as feces. Differences between humans and rodents are attributed to different molecular weight cutoffs for biliary excretion where the molecular weight threshold is higher in humans. Also, in rodents bisphenol A conjugates can be de-conjugated in the gut and be re-circulated back to the liver ("enterohepatic circulation"). Modified from Figure 1 of Taylor et al. (Taylor and others 2011) 


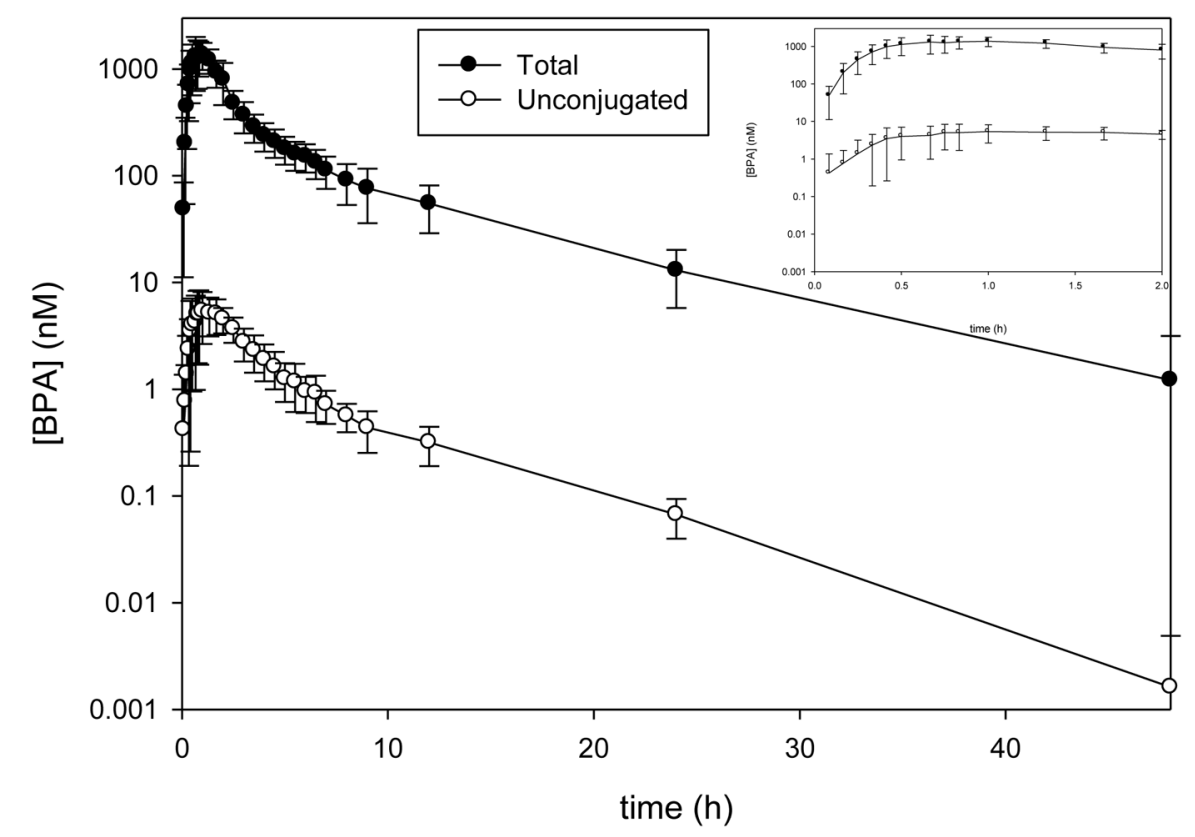

Figure 2. Serum Pharmacokinetics of Unconjugated and Total d6-BPA Following Oral Administration on a Cookie

A common dose $(100 \mu \mathrm{g} / \mathrm{kg} \mathrm{bw})$ was dispensed onto a vanilla wafer and eaten by each of the 14 subjects after insertion of a venous catheter. Blood sampling commenced at $0.083 \mathrm{~h} \mathrm{(5}$ min) post-dosing and continued through $12 \mathrm{~h}$. Single blood samples were also drawn on subsequent days by venipuncture. Unconjugated and total d6-BPA were quantified using UPLC/MS/MS as described in the Method section. Pre-dose samples contained undetectable levels of d6-BPA. The log plots shown below represent the average concentrations $\pm \mathrm{SD}$ $(n=14)$. The inset expands the first 2 hours. 


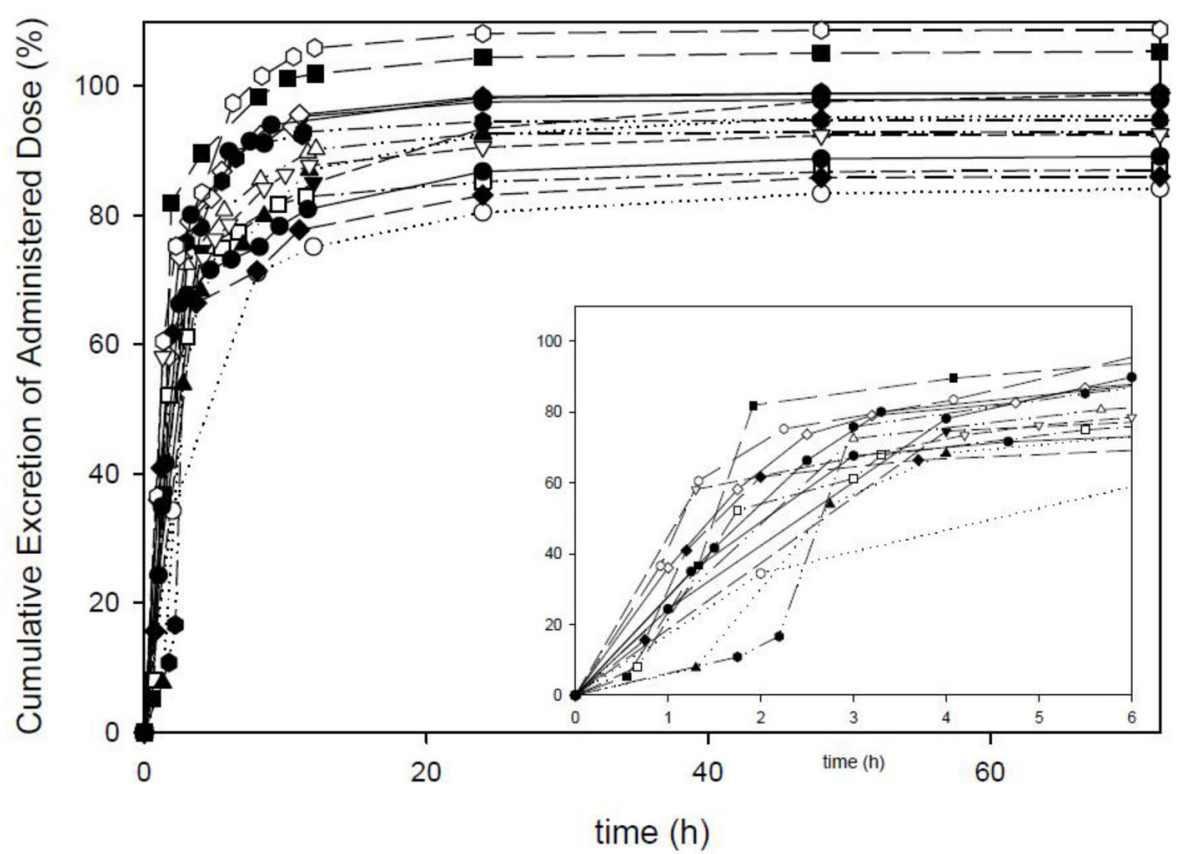

Figure 3. Urinary Excretion of Total d6-BPA in Human Subjects

Cumulative excretion of total d6-BPA was measured after complete enzymatic hydrolysis and is expressed as the percent of d6-BPA dose administered to each subject $(n=14)$. The inset expands the first 6 hours. Due to anomalously low urine recoveries in subjects 4, 5, and 12 a second round of dosing was conducted and those results were used in the aggregate kinetic analysis. 


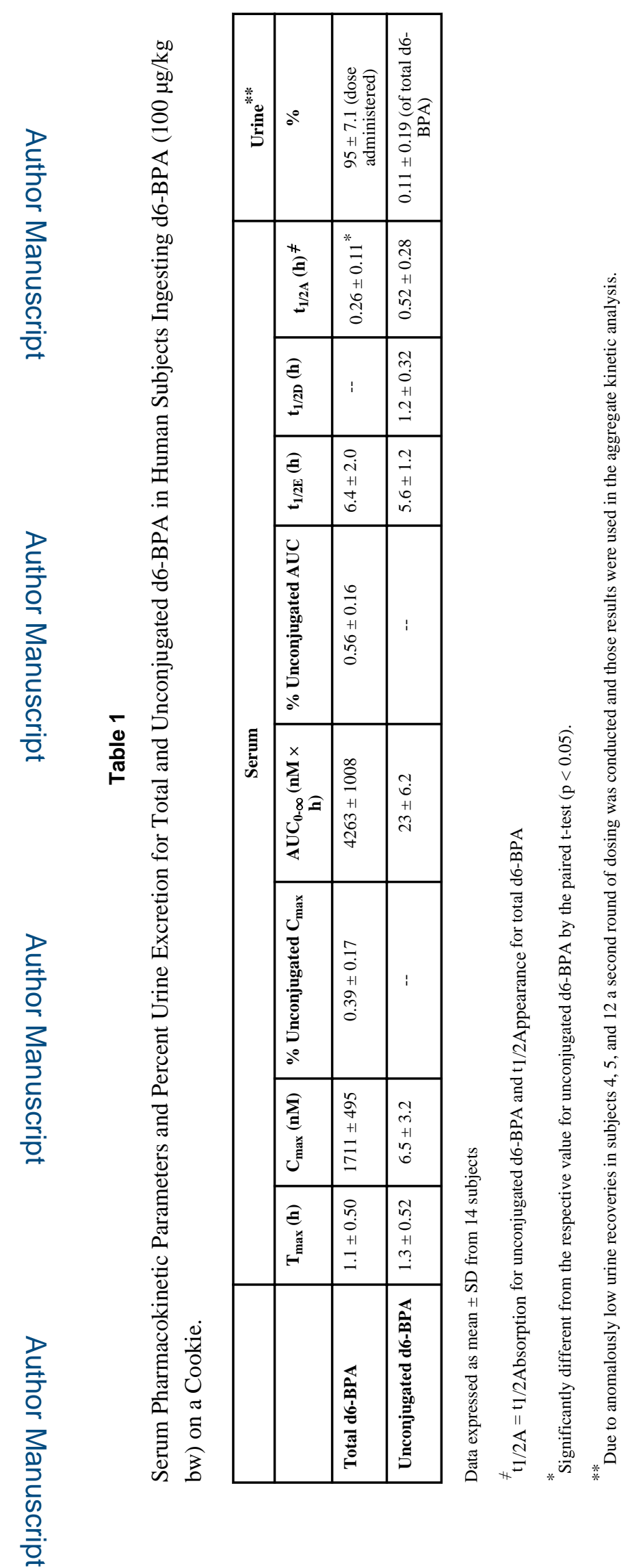

Environ Int. Author manuscript; available in PMC 2016 October 01. 


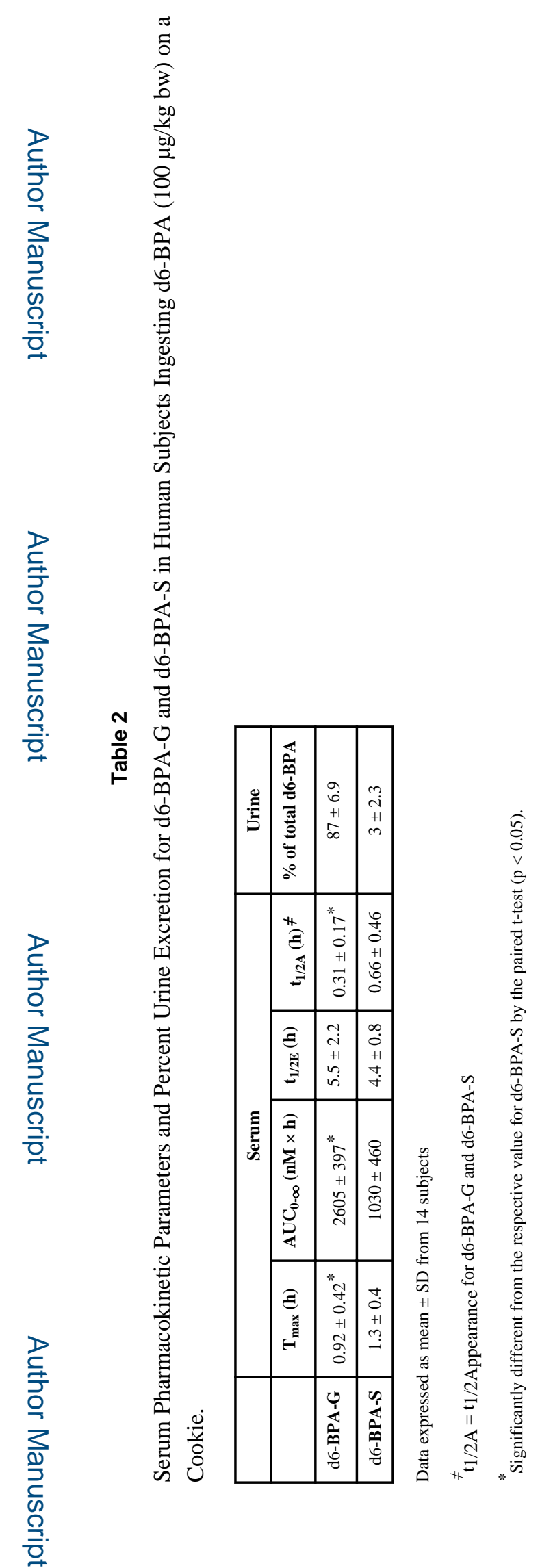

Environ Int. Author manuscript; available in PMC 2016 October 01. 